九州大学学術情報リポジトリ

Kyushu University Institutional Repository

\title{
Local Time Dependence of Pi2 Pulsations Observed along the 210 Magnetic Meridian
}

Li, Yan

Space Sciences Laboratory, Univ. of California

Yumoto, Kiyohumi

Faculty of Sciences, Kyushu University

the 210 MM MAGNETIC OBSERVATION GROUP

https://doi.org/10.5109/1546806

出版情報: 九州大学大学院理学研究院紀要 : Series D, Earth and planetary sciences. 31 (1)， pp.11-18, 2000-12-25. Faculty of Science, Kyushu University

バージョン :

権利関係 : 


\title{
Local Time Dependence of Pi2 Pulsations Observed along the 210 Magnetic Meridian
}

\author{
Yan $\mathrm{LI}^{*}$, Kiyohumi Yumoto \\ and \\ the 210 MM Magnetic ObServation Group
}

\begin{abstract}
Local time dependence of $\mathrm{Pi} 2$ pulsations is studied statistically using the 210 magnetic meridian (MM) data at various latitudes. In totaly, $249 \mathrm{Pi} 2$ events are recognized in one month of data from February, 1995. 68\% of the Pi2 events are observed at night time within this month at the low latitude station Moshiri (MSR; L=1.59). For both occurrence and wave amplitude, there are three maxima at premidnight, slightly post midnight, and prenoon with two minima in the late afternoon and just after sunrise. The amplitudes of three maxima decrease with decreasing magnetic latitude, where the decreasing rates are significantly different. The wave frequency shows different spectral content and different local time dependence at auroral latitude, and middle to low latitudes. The mid- to low-latitude Pi2s have an additional higher frequency component compared with the auroral-latitude Pi2s. The local time dependence of the "equatorial enhancement" is also obtained, which agrees with previous studies at most local times except for the large ratio seen in the few hours after sunrise that has not been previously reported.
\end{abstract}

\section{Introduction}

Pi2 magnetic pulsations (40 to 150 second), by definition, are exited at the time of the substorm expansion onset. The source region is believed to be at the substorm breakup region in the magnetosphere near midnight. Along with the substorm breakup, the formation of the substorm current wedge, and the geomagnetic field dipolarization, a transverse wave propagating along the field line to the auroral-latitude ionosphere and a compressional wave propagating across the field line towards the Earth are thought to be generated (e.g. Yuмото et al., 1989). The former is mostly responsible for high-latitude $\mathrm{Pi} 2$ signatures and the latter for low-latitude Pi2 signatures.

Satellite observations have shown that $\mathrm{Pi} 2$ is a night time phenomena with a maximum occurrence around 21 locate time(LT) (SAKURAI and MCPHERRON, 1983; TAKAHASHI et al., 1992, 1995). However, on the ground Pi2s are observed not only at night time but also in the day time. So far, no local time dependence of ground Pi2s has been studied statistically. Previous studies on the night time Pi2s have shown that both field line oscillations and cavity mode-like compressional oscillations across the field lines are likely to be involved (YUMOTO et al., 1989; TAKAHASHI et al., 1995; SAKA et al, 1996). The spectra of multi-station Pi2 signals at mid, low and equatorial latitudes contain consistent frequency component(s) over both a large latitudinal range and a local time

Manuscript received August 8, 2000 ; accepted October 18, 2000.

${ }^{*}$ Present Adress : Space Sciences Laboratory, Univ. of California, U.S.A. 
range (Yeoman and OrR, 1989; ITONAGA et al., 1992; Li et al., 1998a and b). Equatorial Pi2 studies shows a day time equatorial enhancement, which is attributed to the day time equatorial enhancement of zonal ionospheric conductivity or the presence of the equatorial electrojet (SASTRY et al., 1983; SHINOHARA et al., 1997).

In this paper, we carry out some statistical studies of the local time dependence of Pi2 events occurrence, the wave amplitude and wave frequency observed on the ground, using the $210 \mathrm{MM}$ magnetometer network of stations.

\section{Magnetometer network data}

210 magnetic meridian (MM) magnetometer network comprises fluxgate magnetometers from auroral latitudes to the equatorial region (Yumoto et al, 1996). We have examined one month' $s$ data during February, 1995 from one of the 210 MM low-latitude stations, Moshiri (MSR; see Table 1 for the locations). This is a magnetically quiet month, which provides the advantage in avoiding contamination from other magnetic activity, especially important for the selection of dayside Pi2 events. The magnetometer data has $1 \mathrm{sec}$ resolution. The data are bandpassed through the Pi2 period range (40 to 150 second) before selecting Pi2 events. While MSR serves as the basic data source, we cross check data from other stations within the network to ensure that a signal is not due to a local effect or data problems. For day time Pi2s, we cross check one of the Kyushu University stations in South America, Santa Maria (SMA; Table 1), to ensure the existence of a concurrent nighttime Pi2.

Table1. Geomagnetic Coordinate of the ground stations (Yumoto et al., 1996)

\begin{tabular}{lrrc}
\hline Station & Mlat. & Mlong. & L \\
\hline CHD & 64.75 & 212.12 & 5.46 \\
ZYK & 59.62 & 216.72 & 3.91 \\
MGD & 53.56 & 218.66 & 2.83 \\
MSR & 37.61 & 213.23 & 1.59 \\
GUA & 4.57 & 214.76 & 1.01 \\
POH & 0.19 & 228.96 & 1.00 \\
SMA & -18.73 & 13.18 & 1.11 \\
& & & \\
\hline
\end{tabular}

\section{Local time dependence of $\mathrm{Pi} 2$ wave parameters}

\subsection{Pi 2 Occurrence}

From the February 1995 data at MSR (L=1.59), 249 Pi2 events have been recognized with no restriction on local time. We then sorted the number of events of the resolved $249 \mathrm{Pi} 2 \mathrm{~s}$ into hourly bins. The number of events in each hour is shown as a function of the local time in Figure 1. Out of the $249 \mathrm{Pi} 2$ events, $68 \%$ are observed at night time within this month (or 28 days) at the low latitude station MSR. At night time between 20 and $03 \mathrm{LT}$ the number of Pi2 events in each hour ranges between 12 and 24 . Two maxima can be seen at night time, one premidnight between 21 
and $22 \mathrm{LT}$ (24 Pi2s), and another postmidnight between 01 and $03 \mathrm{LT}$ (20 Pi2s in each hour). There are two minima, one in the late afternoon between 16 and $17 \mathrm{LT}$ (4 Pi2s), and another in early morning between 06 and $08 \mathrm{LT}$ ( $4 \mathrm{Pi} 2 \mathrm{~s}$ in each hour). In the daytime there is a maximum between 10 and 11 LT (10 Pi2s).

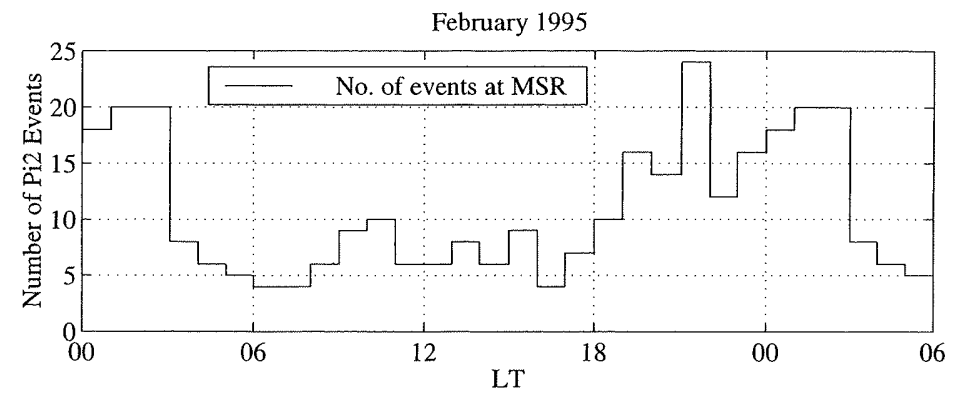

Fig. 1. Number of Pi2 events in each hour at MSR $(L=1.59)$ as a function of local time.

\subsection{Wave amplitude}

Using the $249 \mathrm{Pi} 2$ events, we studied the wave amplitude distribution with local time at stations from high latitudes to the dip equator, i.e. Chokordahk (CHD, L=5.46), Zryanka (ZYK, 3.91), Magadan (MGD, 2.83), Moshiri (MSR, 1.59), Guam (GUA, 1.01) and Ponapei (POH, 1.00) (see Table 1). The amplitude of the horizontal wave component, $\mathrm{P}=(\mathrm{H} 2+\mathrm{D} 2) 1 / 2$, was averaged in each hour and weighted by the number of events in the corresponding hour. The averaged amplitude of $\mathrm{P}$ in each hour is shown as a function of local time in Figure 2 for the above mentioned six stations,
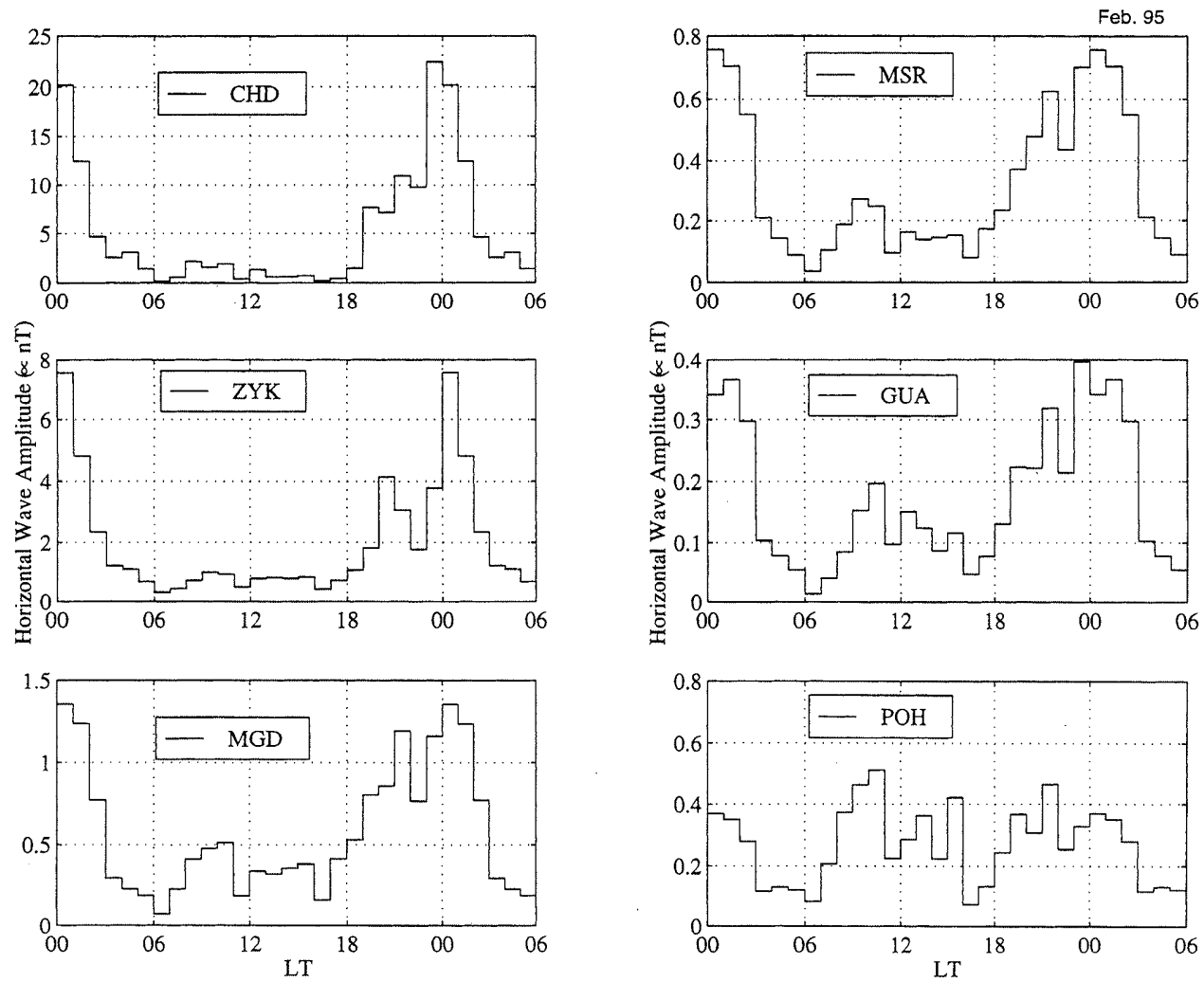

Fig. 2. Hourly averaged amplitude of horizontal Pi 2 componant (see text for definition) as a function of local time at six stations marked in each panel from auroral latitudes to the equator. 
respectively. At CHD there are a sharp maximum between $23 \mathrm{LT}$ and local midnight and some a possible minor maximum at around $21 \mathrm{LT}$. The wave amplitude at $\mathrm{CHD}$ in the daytime is one tenth compared to that at night time. At the mid and low-latitude stations (ZYK, MGD, MSR and GUA), there is a maximum between local midnight and $01 \mathrm{LT}$ and a smaller peak between 21 and 22 LT. In the daytime the amplitude is significant but much smaller than that at night time, and the amplitude is greater in the morning with a maximum between 10 and $11 \mathrm{LT}$. At the equatorial station $\mathrm{POH}$, the amplitude in the day time is slightly greater than that at night time, and in the morning there is a maximum between 10 and $11 \mathrm{LT}$. At night time the amplitude also shows two peaks, with the one between 21 and $22 \mathrm{LT}$ is showing greater amplitude than the second peak between local midnight and $01 \mathrm{LT}$. From CHD to the middle and low latitudes, the three peaks of the wave amplitude decrease at different rates with latitude.

Figure 3a shows the amplitude profiles of the two night time peaks and the day time peak. The peak around midnight (hereafter the "night peak" , diamond symbols and a dot-dashed line) decreases much faster than the premidnight peak (hereafter the "evening peak" , cross symbols and a dashed line). The night peak decreases from $22 \mathrm{nT}$ at CHD to about $1 \mathrm{nT}$ at MGD, and from MGD to the dip equator, the amplitude only decreases by a small amount. The evening peak decreases from $12 \mathrm{nT}$ at CHD to $1 \mathrm{nT}$ at MGD, then gradually decreases to $0.3 \mathrm{nT}$ at GUA, with a slight increasing is seen from GUA to $\mathrm{POH}$ at the dip equator. This is seen in Figure $3 \mathrm{~b}$ which is a

(a)

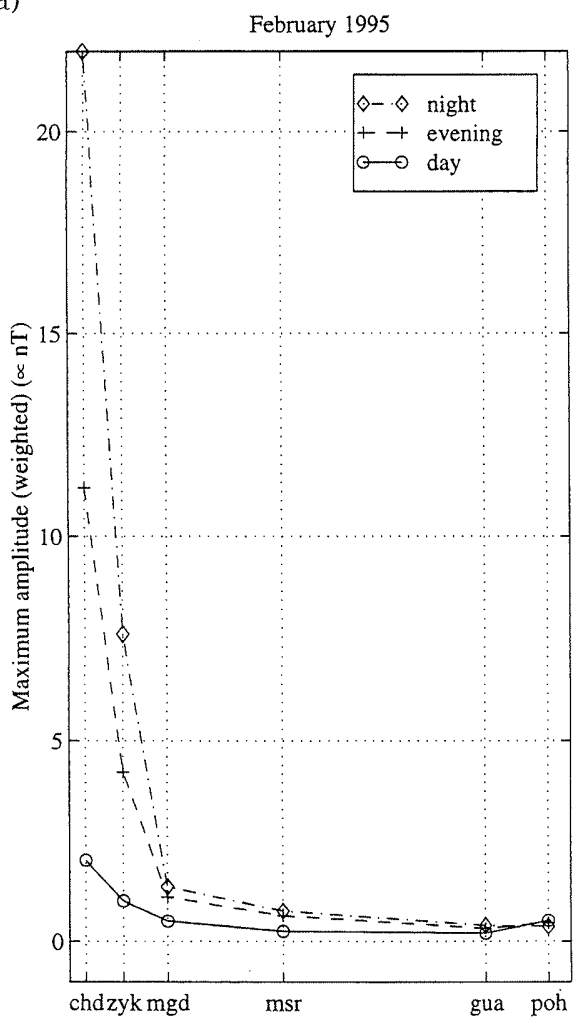

(b)

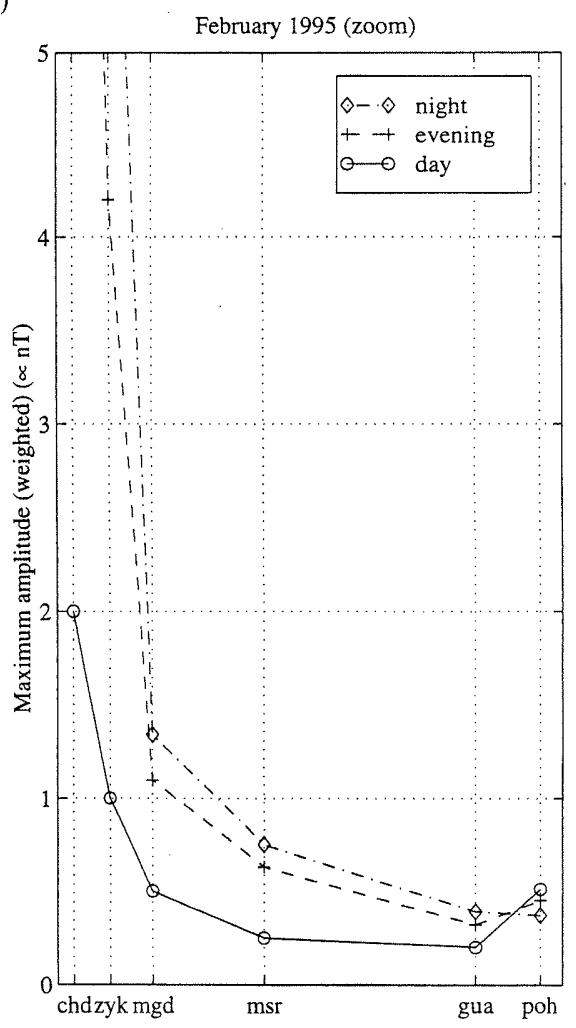

Fig. 3. Left panel: The different latitudinal variation of three maxima at premidnight, postmidnight and prenoon. Right panel: A zoom of the left panel in emphasising the equatorial enhancement from GUA to $\mathrm{POH}$. 
zoom of Figure 3a, and the dip equator enhancement is a curious feature, not been previously reported. The day time peak (hereafter the "day peak" , circle symbols and a solid line) decreases within a very small amplitude range of 2 to $0.2 \mathrm{nT}$ from auroral latitude of CHD to low latitudes of GUA, and again a clear increase in amplitude can be seen from GUA to $\mathrm{POH}$ at the dip equator in Figure $3 \mathrm{~b}$. At all stations, the wave amplitude decreases with local time away from around midnight, and there are two minima, one between 16 and $17 \mathrm{LT}$ and another between 06 and $07 \mathrm{LT}$ (Figure 2).

In Figure 4 we present the amplitude ratio between POH and GUA as a function of local time. The ratio is between 0.8 and 1.2 two hours prior to and 4 hours after the local midnight. The ratio tends to increase gradually towards both dawn and dusk. In the hour prior to local noon, the ratio is 2.3 , and the hour post local noon, the ratio is around 1.9. From noon the ratio increases abruptly towards both the dawn and dusk. The maximum ratio reaches 6.2 between 06 and $07 \mathrm{LT}$.

In the afternoon between 15 and $16 \mathrm{LT}$, the ration is 3.7 . The local time dependence agrees quite well with SASTRY et al. (1983) except for the few hours just after sunrise. The amplitude ratio around the local noon agrees with the previous reports that daytime Pi2 equatorial enhancement is at a factor about 2 (SASTRY et al., 1983; SHINOHARA et al., 1997). Shinohara et al. (1997) found that the average amplitude at an equatorial station between 22 to $03 \mathrm{LT}$ is slightly depressed compared to a low-latitude station.

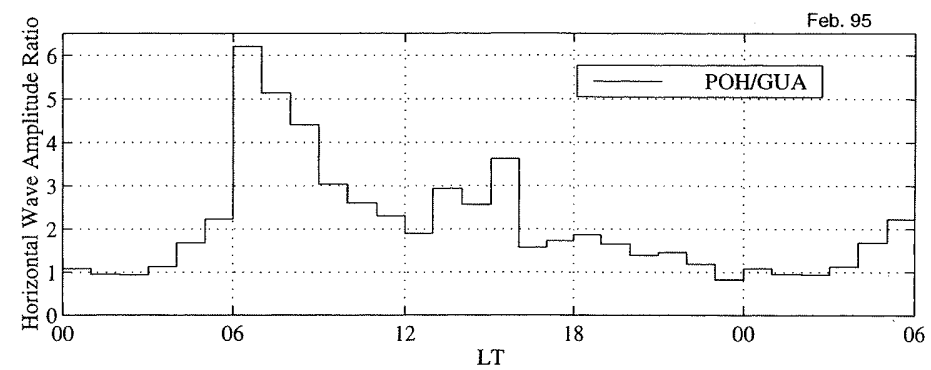

Fig. 4. The ratio of the forizontal amplitude between POH and GUA as a function of local time. A large ratio is seen in the few hours after sunrise.

\subsection{Wave frequency}

The amplitude spectral density of each event of the $249 \mathrm{Pi} 2 \mathrm{~s}$ were estimated and the predominant frequency of each event found. The predominant frequencies of the events in each hour were then averaged. The hourly averaged frequency is shown as a function of local time at the six stations in Figure 5. At hig-latitude station CHD ( $\mathrm{L}=5.46)$, the frequency is between 8 and 12 $\mathrm{mHz}$ over the wholeday with no significant maximum or minimum. At mid- and low-latitude stations a maximum frequency of about $15 \mathrm{mHz}$ can be seen around local midnight and a lower frequency around $10 \mathrm{mHz}$ in the evening hours, but the tendency is not clear at other times. At the equatorial station $\mathrm{POH}$, the frequency shows the same local time dependence and values as the mid- and low-latitudes at night time, and in the day time (06-18LT) the frequency is between 10 and $12 \mathrm{mHz}$, the same frequency range as the auroral latitude Pi2s. The sharp frequency maximum at MGD and POH between 05 and $06 \mathrm{LT}$ is interesting. There are only $5 \mathrm{Pi} 2 \mathrm{~s}$ in this hour, and the data is reliable for these events. Whether this is some local or temporal effect or a persistent feature is not clear at the moment. 

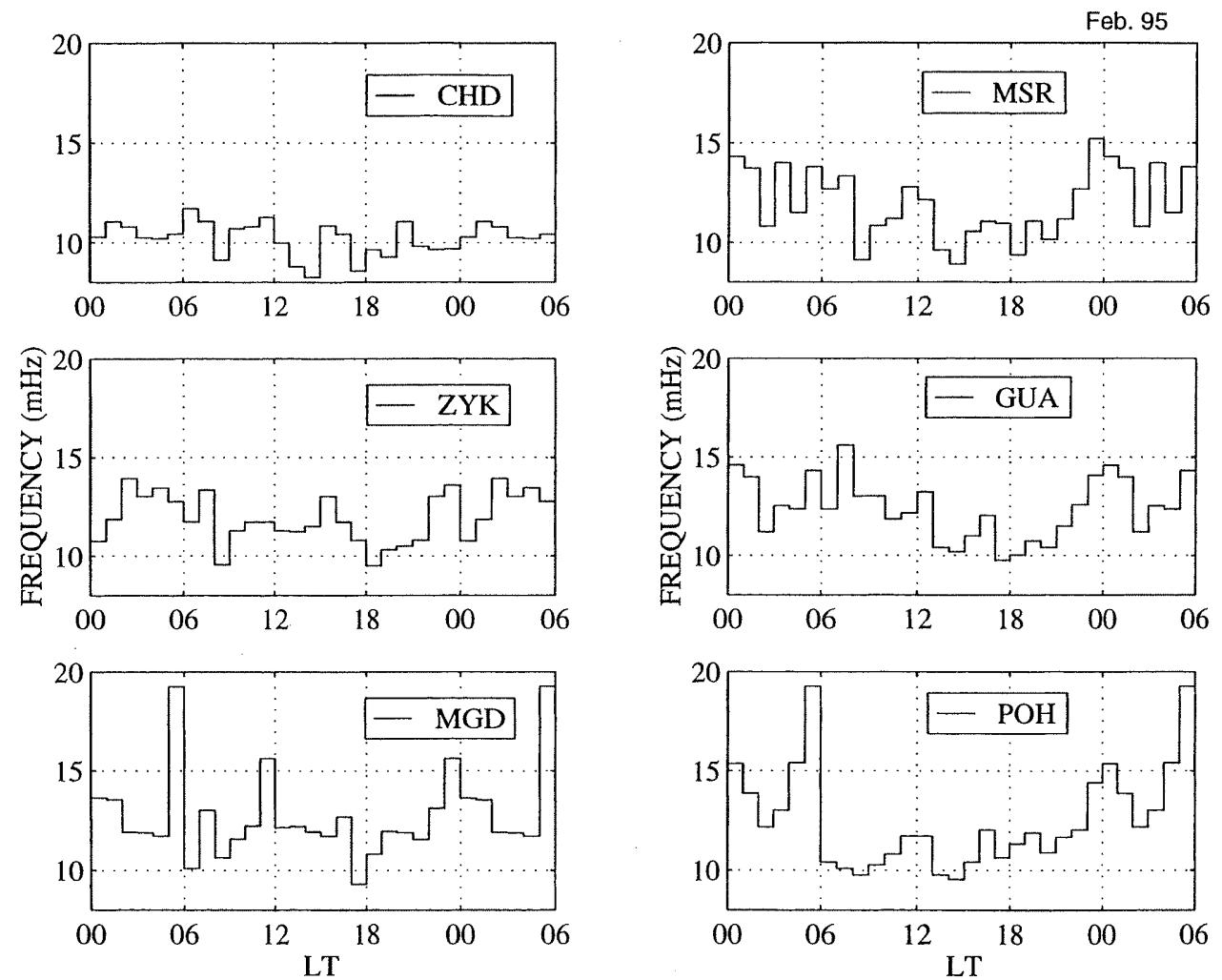

Fig. 5. Hourly averaged frequency of Pi 2 pulsations as a function of local time at six stations marked in each panel from auroral latitudes to the equator.

\section{Summary and discussions}

We have found that at a low latitude station $\mathrm{L}=1.59,68 \%$ of $249 \mathrm{Pi} 2$ events occur at night time within a winter month; at night time there are two maxima, one premidnight (24 $\mathrm{Pi} 2 \mathrm{~s})$ between 21 and $22 \mathrm{LT}$, and another postmidnight (20 Pi2s in each hour) between 01 and $03 \mathrm{LT}$; there are two minima, one in the late afternoon (4 Pi2s) between 16 and $17 \mathrm{LT}$, and another in early morning (4 Pi2s in each hour) between 06 and $08 \mathrm{LT}$; at daytime there is a maximum between 10 and $11 \mathrm{LT}$.

Most Pi2 waves seen from subauroral latitude through to low latitude are confined to the night time. In the equatorial region, similar wave amplitudes appear during the day and night time, although the number of events seen in the day time are much less than that at night time. There are three distinct amplitude maxima, the night peak, the evening peak and the day peak. The night peak, decreases with decreasing latitudes faster than the evening peak. The day peak is essentially flat. From low latitudes to the equatorial region, the night peak decreases slightly, the evening peak increases and the day peak increases more obviously, suggesting the equatorial enhancement. There are two amplitude minima seen at all mid to low latitude stations in the late afternoon and around the sunrise. The local time dependence of both the occurrence and wave amplitude does not seem to support the suggestion that a cavity resonance is established in the entire inner magnetosphere, including the dayside hemisphere. Previous satellite observations have shown that Pi2s are night time phenomena and are not observed in the dayside magnetosphere (TAKAHASH et al., 1995). Li et al. (1998a) found that daytime equatorial Pi2s (case study) have a 
common frequency component with auroral Pi2s, while the frequency does not appear at the midlow-latitudes. We speculate that different mechanisms are responsible for nightside and dayside low latitude Pi2s. It is likely that the ionosphere should play a role in the propagation of Pi2 pulsations to the dayside hemisphere. The observational facts suggest an instantanous penatration of the electric field in the Pi 2 frequency range from the polar region to the the equatorial region through the ionosphere (SHINOHARA et al. and references therein, 1997).

The amplitude ratio between the equatorial station and the low latitude stations is local time dependent (Figure 4). This result agrees with previous studies except for the large ratio at the few hours after sunrise that has not been reported.

At auroral latitudes, the local time frequency dependence is not distinct, but at mid and low latitudes, higher frequenies predominant at the local times corresponding to the night peak, and lower frequency (similar with that at the auroral latitude) predominants at the local times corresponding to the evening peak. It seems reasonable to speculate that there is one wave mode at auroral latitudes, but two wave modes suppose at mid and low latitudes on the nightside, which supports some previous studies (YEOMAN and ORR, 1989; LI et al, 1998b). One of the wave modes is generated at auroral latitude, presumably field line oscillations, and the other compressional mode across the field lines towards low latitudes. Statistically, the low latitude daytime wave frequency is different from (lower than) the night time frequency, but similar to auroral latitude frequency. This implies that daytime Pi2s might be directely transmitted from the auroral region through perhaps the ionosphere, rather than being a result of a global cavity resonance.

\section{Conclusion}

From this statistical study, we have found that not all Pi2s can be observed globally. There should be over half of the observed Pi2s that do not have signatures in the day time at most latitudes except for the equatorial region. The reason is yet to be understood. We see that Pi2s exhibit different features at different locations and local times. It is evident that there should be a change of the predominant wave mode at around the plasmapause latitude at the local times around midnight, in this situation it may be expected that a lower frequency component will dominate at the auroral latitudes and a higher frequency component at middle to low latitudes. Further more, if it is cavity resonance that gives rise to the higher frequency component, the cavity resonance should only be significant around midnight. Daytime Pi2s are possibly caused by a different mechanism that at the moment is only a speculation.

\section{Acknowledgments}

Our sincere thanks go to all the members of the $210 \mathrm{MM}$ magnetic Observation Group for their ceaseless supports, and K. Shiokawa, STEL, Nagoya University for data archives. Finacial support was given by the Ministry of the Education, Science and Culture of Japan in the forms of Grants-inAid for Overseas Scientific Survey $(06044094,08041105,10041122)$ and for Data Base.

\section{References}

Itonaga, M., Kitamura, T.-I., Saka, O., Tachihara, H., Shinohara M. and Yoshikawa, A. (1992): Discrete spectral structure of low-latitude and equatorial Pi2 pulsation, J. Geomag. Geoelectr., 44, 253 - 
259.

Li, Y., Fraser, B.J., Menk, F.W., Webster, D.J. and Yumoto, K. (1998a): Properties and sources of low and very low latitude Pi2 pulsations, J. Geophys. Res., 103, 2343-2358.

LI, Y., K. Yumoto, M. Itonaga, M. Shinohara, T.-I. Kitamura and CPMN group (1998b): Equotrial Pi2s as indicators of substorms and the relation between dayside and nightside Pi2s, in Substorms - 4, edited by S. KoKubun and Y. Kamide, Kluwer Academic Publishers, Dordrecht, London, Boston, pp. 555-558.

SAKURAI, T. and MCPHERRON, R.L., (1983): Satellite observations of Pi2 activity at synchronous orbit, $J$. Geophys. Res., 88,7015 - 7027.

SaStry, T.S., Sarma Y.S. Sarma, S.V.S. and Sanker Narayan P.V., (1983): Day-time Pi pulsations at equatorial latitudes, J. Atmos. Terr. Phys., 45, 733 - 741.

Shinohara, M., K. Yumoto, A. Yoshigawa, O. Saka, S. I. Solovyev, and the 210 Mm Magnetic Observation Group (1997): Wave characteristics of daytime and nighttime Pi2 pulsations at the equatorial and low latitudes, Geophys. Res. Lett., 24, $2279-2282$.

TAKAHASHI, K., OHTANi, S. and AnderSon, B.J. (1995): Statistical analysis of Pi2 pulsations observed by the AMPTE CCE spacecraft in the innde magnetosphere, J. Geophys. Res., 100, $21929-21941$.

Yumoto, K., K. TAkahashi, T. Saito, F.W. Menk, B.J. Fraser, T.A. Potemra, and L.J. Zanetti,(1989): Some aspects of the relation between Pi 1-2 magnetic pulsations observed at $L=1.3-2.1$ on the ground and substorm-associated magnetic field variations in the near-earth magnetotail observed by AMPTE/CCE, J. Geophys. Res., 94, 3611-3618.

Yuмото, K. (1995): Initial results from the 210 magnetic meridian project - Review, J. Geomag. Geoelectr., 47, $1197-1213$.

Yumoto, K., and the 210 MM Magnetic Observation Group (1996): The STEP 210 magnetic meridian network project, J. Geomag. Geoelectr., 48, $1297-1309$. 